\title{
Pituitary
}

\section{Long-Lasting Intrinsic Optical Changes Observed in the Neurointermediate Lobe of the Mouse Pituitary Reflect Volume Changes in Cells of the Pars Intermedia}

\author{
P. Kosterin $^{\text {a }}$ A.L. Obaid ${ }^{a} \quad$ B.M. Salzberg ${ }^{a, b}$ \\ Departments of a Neuroscience and ${ }^{b}$ Physiology, University of Pennsylvania School of Medicine, \\ Philadelphia, Pa., USA
}

\section{Key Words}

Chloride movement $\cdot \mathrm{GABA}_{\mathrm{A}}$ receptor $\cdot$ Light scattering • Neurohypophysis $\cdot$ Neurointermediate lobe $\cdot$ Pituitary • Volume changes

\begin{abstract}
Background/Aims: Complex intrinsic optical changes (light scattering) are readily observed in the neurointermediate lobe of the mouse pituitary gland following electrical stimulation of the infundibular stalk. Our laboratory has previously identified three distinct phases within the light scattering signal: two rapid responses to action potential stimulation and a long duration recovery. The rapid light scattering signals, restricted to the neurohypophysial portion (posterior pituitary) of the neurointermediate lobe, consist of an Ewave and an S-wave that reflect excitation and secretion, respectively. The E-wave has the approximate shape of the action potential and includes voltage- and current-related components and is independent of $\mathrm{Ca}^{2+}$ entry. The S-wave is related to $\mathrm{Ca}^{2+}$ entry and exocytosis. The slow recovery phase of the light scattering signal, which we designated the R-wave, is less well characterized. Methods: Using high temporal resolution light scattering measurements, we monitored intrinsic optical changes in the neurointermediate lobe of the mouse pituitary gland. Pharmacological inter-
\end{abstract}

\section{KARGER}

Fax +4161306 1234

E-Mail karger@karger.ch

www.karger.com (c) 2010 S. Karger AG, Basel

$0028-3835 / 10 / 0923-0158 \$ 26.00 / 0$

Accessible online at:

www.karger.com/nen ventions during the measurements were employed. Results: The data presented here provide optical and pharmacological evidence suggesting that the R-wave, which comprises signals from the posterior pituitary as well as from the pars intermedia, mirrors volume changes in pars intermedia cells following a train of stimuli applied to the infundibular stalk. These volume changes were blocked by the GABA-receptor antagonists bicuculline and picrotoxin, and were mimicked by direct application of GABA in the absence of electrical stimulation. Conclusions: These results emphasize the importance of central GABAergic projections into the neurointermediate lobe, and the potential role of GABA in effecting hormone release from the pars intermedia.

Copyright ๑ 2010 S. Karger AG, Basel

\section{Introduction}

It is generally accepted that $\mathrm{Ca}^{2+}$-mediated secretion of the peptide hormones vasopressin and oxytocin from the neurohypophysis is accompanied by cell surface and volume changes associated with the fusion of secretory vesicles (dense-core granules) with the plasma membrane $[1,2]$, and the release of their contents. There is also evidence [3] for the convective flow of water during this process. However, exocytosis (and endocytosis) are rapid 
processes $[1,4]$, whereas swelling that may be due, for example, to GABA-mediated increases in membrane transport, takes minutes [5]. All of these processes correlate with changes in the volume [6] and/or refractive index of cells and can thus be recorded as long-term changes in the intrinsic optical properties of whole tissue, as in the case of the mouse neurohypophysis [7]. While a change in refractive index could account, in principle, for changes in the intrinsic optical properties of tissues [8], in most instances volume changes are responsible [9]. Using a modified (dynamic high-bandwidth) atomic force microscope, we recently demonstrated that the rapid changes in light scattering (E-wave and S-wave) [7] exhibited by the mouse neurohypophysis are, indeed, associated with volume changes in that tissue [10]. The light scattering changes associated with exocytosis from mammalian nerve terminals were originally observed in a preparation of mouse pituitary (fig. 1a) in which the anterior pituitary (pars distalis) was separated from the neurointermediate lobe [neurohypophysis, also known as pars nervosa or posterior pituitary (PP)] and pars intermedia (PI) [7]. In these experiments, the axons passing through the infundibular stalk of the pituitary were stimulated electrically and the resulting changes in transmitted light through the neurointermediate lobe were recorded as light scattering signals. These intrinsic optical changes in the mammalian neurohypophysis are reliable tools for the study of excitation-secretion coupling. They can be recorded from an intact preparation under near-physiological stimulation conditions, providing an opportunity to observe, in real time, processes associated with hormone release, and to alter these processes by means of pharmacological agents.

The changes in light scattering previously observed [7, 11] in the neurointermediate lobe of the mouse (and other rodents) include at least three phases: two rapid light scattering signals consisting of an E-wave and an S-wave [7] (fig. 1b) that reflect excitation and secretion, respectively, and rise within milliseconds of the arrival of individual action potentials, and a long duration recovery (Rwave) lasting seconds to minutes (fig. 1c).

The E-wave includes voltage- and current-related components and is independent of $\mathrm{Ca}^{2+}$ entry, while the $\mathrm{S}$-wave is related to $\mathrm{Ca}^{2+}$ entry and exocytosis. The Ewave is sensitive to specific ionic and pharmacological interventions that alter membrane voltage and current (e.g. changes in $\left[\mathrm{Na}^{+}\right]_{\mathrm{o}},\left[\mathrm{K}^{+}\right]_{\mathrm{o}}$ and $\left[\mathrm{Ca}^{2+}\right]_{\mathrm{o}}$, and specific ion channel blockers, e.g. 4-AP or TTX). The S-wave, on the other hand, does not occur in the absence of the E-wave, and can be altered by experimental interventions known
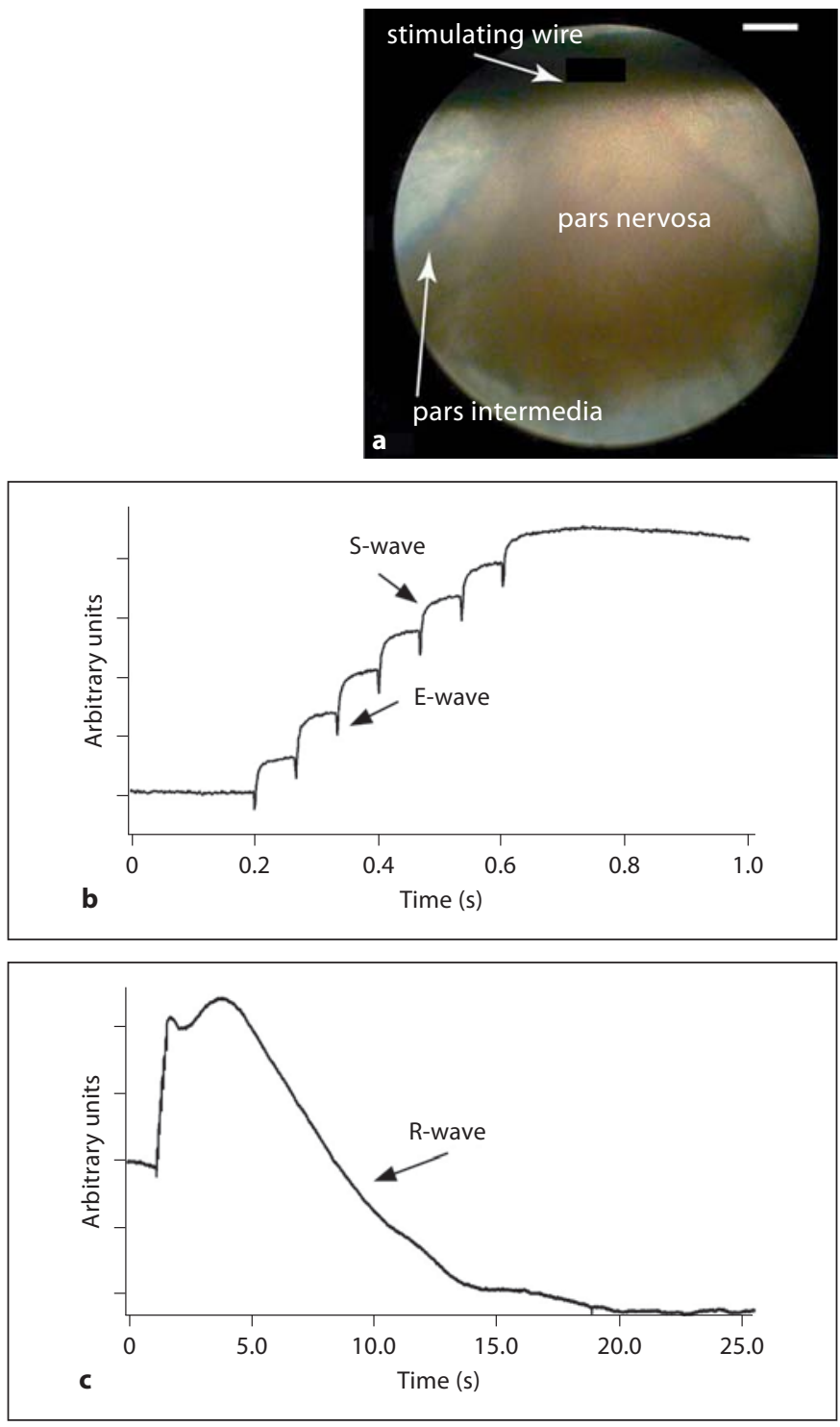

Fig. 1. Light scattering changes recorded from the mouse neurointermediate lobe in response to trains of seven electrical stimuli ( $500 \mu \mathrm{s}$ at $16 \mathrm{~Hz}$ for $410 \mathrm{~ms}$ ) applied to the infundibular stalk. a View of the mouse neurointermediate lobe in a dissecting microscope. Scale bar $=0.2 \mathrm{~mm}$. b The intrinsic optical signal (light scattering change) recorded at $670 \mathrm{~nm}$. The rapid downstrokes (E-waves) reflect the arrival of the action potentials (and action currents) in the terminals of the neurohypophysis (PP), and the sustained upward deflections (S-waves, increased transparency) represent decreases in large-angle light scattering that are closely coupled to secretion of arginine vasopressin and oxytocin. c Another recording of the light scattering change in response to the same stimulus train as in $\mathbf{b}$, but displayed on a contracted time base to show the long duration response (R-wave). In all the optical signals, an increase in transmitted light intensity (decreased light scattering) is plotted upward. All of the traces here and in the following figures were recorded without averaging using a single silicon PIN photodiode mounted behind an adjustable diaphragm in the image plane of a compound microscope. 
to modulate neuropeptide secretion (e.g. $\mathrm{Ba}^{2+}$ substitution for $\mathrm{Ca}^{2+}$, changes in $\left[\mathrm{Ca}^{2+}\right]_{0}$, stimulation frequency, $\mathrm{D}_{2} \mathrm{O}$-substitution for $\mathrm{H}_{2} \mathrm{O}$ and application of $\mathrm{Ca}^{2+}$-channel blockers [7, 12, 13] and caffeine [14]). The E-wave, in particular, reflects the arrival of the action potential and associated action currents at the neurohypophysial terminals (and secretory varicosities [15]), and correlates with the fluorescence and absorption signals observed with voltage-sensitive dyes [12,13,16-18], with the rising edge of signals from $\mathrm{Ca}^{2+}$-sensitive dyes [17, 19], and with volume changes (the 'mechanical spike') recorded with a high-bandwidth modified atomic force microscope [10]. In short, the E-wave of the light scattering signal constitutes a voltage- and current-related component exhibiting the general shape of the invading action potential [16], and is followed by the S-wave, a component that reflects the processes of Ca entry and exocytosis.

The slow recovery phase of the light scattering signal (the R-wave), however, is less well understood. Previous experiments [20] had shown that this recovery phase is extremely sensitive to chloride replacement $(90 \%)$ by impermeant anions (e.g. gluconate and methylsulfonate), and to blocking of chloride transport with stilbene derivatives such as 4 -acetamido-4-isothiocyanato-stilbene2,2-disulfonic acid (SITS) and 4,4'-diisothiocyanatostilbene-2,2'-di-sulfonic acid (DIDS), and suggested that the R-wave may reflect transmembrane chloride movements coupled to volume changes in the tissue. All of these signals exhibit some wavelength dependence, especially in the late phase (fig. 2), but are readily measured from 400 to $1,000 \mathrm{~nm}$.

The mammalian pituitary gland is a complex tissue. Developmentally [21] the pituitary derives from two different sources and comprises histologically different tissues. The anterior lobe, together with the PI is an upgrowth of ectoderm from the roof of the stomatodeum, while the PP is derived from the neurectoderm. Although it is relatively simple to separate the anterior pituitary from the rest of the pituitary because of the intraglandular cleft, the embrace of the PP by the PI, in which it is nestled, is so intimate that it is impossible to completely separate them mechanically. Because the intrinsic optical changes were actually measured from the composite tissue that is the neurointermediate lobe [7], and because the fast and slow components of the signal are pharmacologically separable, it seemed important to attempt to disentangle the anatomical origins of the observed light scattering changes, and to analyze, as much as possible, this complex signal into components that could be assigned to either the nerve terminals of the PP or to the cell bodies of the PI.

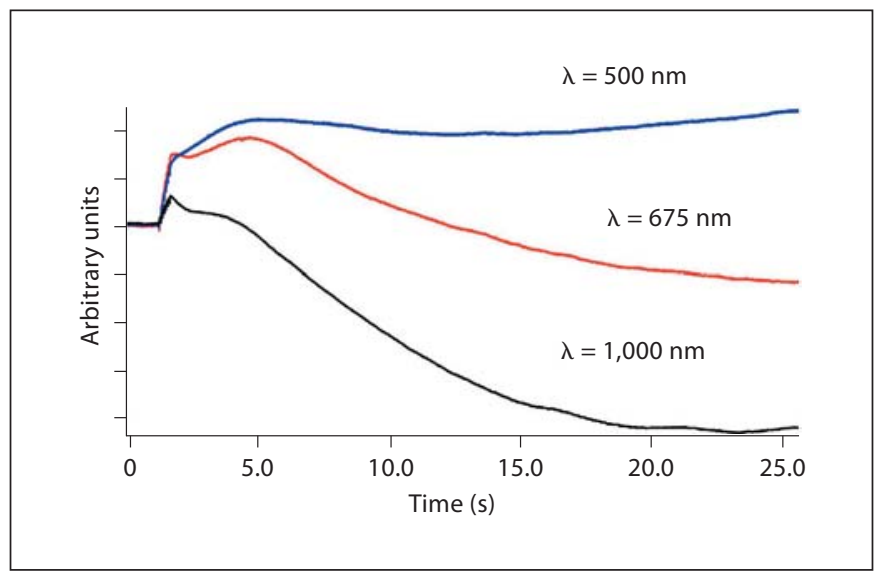

Fig. 2. Wavelength dependence of the light scattering change recorded from the neurointermediate lobe (PP plus PI) in response to the same train of seven stimuli as in figure 1. Recordings obtained at representative wavelengths.

Here, we achieve a partial differentiation of the light scattering signal, and we characterize more fully its recovery phase. Our data demonstrate that the R-wave includes light scattering contributions from both PP and PI and its normal shape requires the anatomical integrity of the neurointermediate lobe. The PI component of the Rwave is determined by the response of these cells to GABA released upon stimulation of the infundibular stalk, and is eliminated by $\mathrm{GABA}_{\mathrm{A}}$-receptor blockers. These experiments provide optical and pharmacological evidence for a central GABAergic innervation of PI and they also suggest that light scattering measurements may be used to monitor processes associated with secretion and their response to experimental intervention.

\section{Materials and Methods}

The neurointermediate lobe was obtained from CD-1 mice in the following manner. Females, 30-40 days old, were sacrificed by guillotine and exsanguinated. The head was pinned to the bottom of a Sylgard-lined dissection dish and its skin was removed from the skull. The skull was then opened along the dorsal midline and the upper portion removed bilaterally. The brain was reflected caudally and removed, after cutting optic and olfactory nerves under a low-power dissecting microscope. During this procedure, the infundibular stalk is automatically ruptured, leaving an infundibular stump and the entire pituitary gland in the base of the skull, held in place by thin connective tissue. Oxygenated mouse Ringer's solution (in mM: $154 \mathrm{NaCl}, 5.6 \mathrm{KCl}, 1 \mathrm{MgCl}_{2}$, 2.2 $\mathrm{CaCl}_{2}, 10$ glucose, 20 HEPES, adjusted to $\mathrm{pH} 7.4$ with $\mathrm{NaOH}$ ) was circulated over the pituitary, during the removal of the gland 


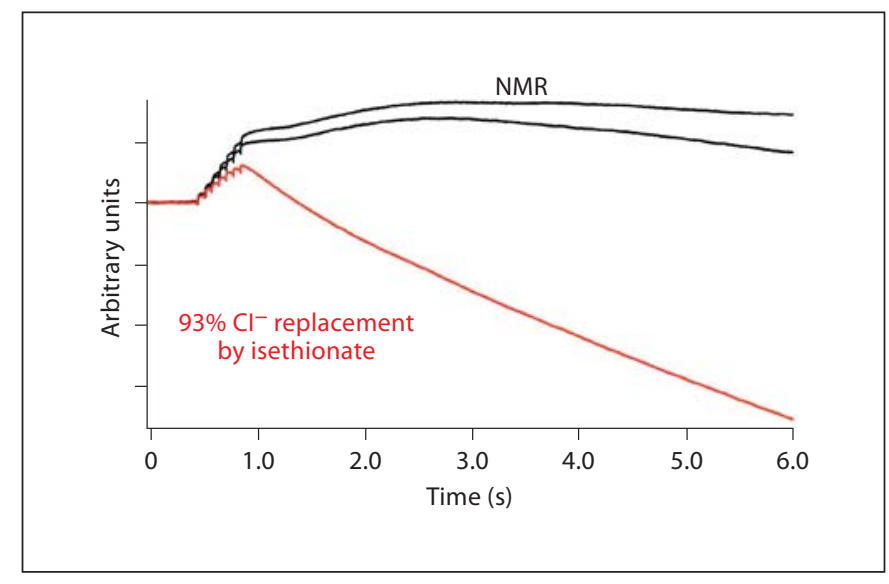

Fig. 3. The effect of impermeant anion (isethionate) substitution for chloride in the bathing solution on the light scattering change recorded from the neurointermediate lobe (PP plus PI). Signals recorded in normal mouse Ringer's solution (NMR) before and after isethionate substitution are shown in black. The red trace exhibits the response to the same stimuli as in figure 1 when $93 \%$ of the chloride in the bathing solution was replaced with isethionate.

using iridectomy scissors and fine forceps. Once the pituitary was isolated, the anterior pituitary (pars distalis) could be separated from the neurointermediate lobe, comprising the neurohypophysis (pars nervosa) plus the PI. The PI consists of a delicate lacework of tissue surrounding the neurohypophysis and provides a convenient site for pinning to the bottom of an experimental chamber while preserving the integrity of the neurohypophysis.

The neurointermediate lobe was pinned down (with the neurohypophysis facing upward) on the thin Sylgard bottom of a simple chamber so that the infundibular stalk could be clasped between a pair of Pt-Ir (90\%-10\%) electrodes coated with Teflon except where they contact the infundibulum. Brief shocks (80$100 \mathrm{~V}$ ), lasting between 300 and $500 \mu \mathrm{s}$, were delivered through a stimulus isolator, and the resulting changes in the transparency of the neurointermediate lobe were recorded [7] using a large area PIN silicon photodiode (PV-444, Perkin Elmer Optoelectonics, Vaudreuil, Qué., Canada) and a current-to-voltage converter having a $1-\mathrm{M} \Omega$ feedback resistor together with a $500 \times$ second stage amplifier. Illumination was provided by either a high power 740 nm LED (Roithner LaserTechnik, Vienna, Austria) [22, 23] or a 100 -W tungsten-halogen lamp with a $675 \pm 25 \mathrm{~nm}$ (Chroma Technology, Brattleboro, Vt., USA) filter. The photodiode was positioned in the image plane of a Zeiss UEM upright microscope behind an adjustable diaphragm, or mask, so that only light passing through the preparation was monitored. Unless otherwise noted, the objective was a $20 \times 0.5$ n.a. HCX APO water immersion lens (Leica, Solms, Germany). With adequate oxygenation, the resulting intrinsic optical signals can easily be recorded for several hours.

In all of the optical records, the ordinate scale represents changes in transmitted light intensity plotted in arbitrary units. The aggregate $\Delta \mathrm{I} / \mathrm{I}$ during the seven stimuli was typically $\sim 5 \times$ $10^{-3}$. The plots shown are representative of 5-20 replicate experiments.

Intrinsic Optical Changes in Mouse Pituitary

\section{Results}

Figure 3 illustrates an experiment that is consistent with the outcome of some early experiments published only in abstract form [20] which we interpreted as demonstrating a direct link between $\mathrm{Cl}^{-}$movements and the $\mathrm{R}$-wave of the light scattering signal. These results, together with the presence of central GABAergic innervation of the mouse neurointermediate lobe [24-29], and the presence of $\mathrm{GABA}_{A}$ and $\mathrm{GABA}_{\mathrm{B}}$ receptors on cells of the PI [30], led us to explore whether or not the R-wave was monitoring the physiological effects of GABA released when the infundibular stalk is stimulated electrically. Indeed, figure 4 demonstrates that the R-wave is sensitive to the $\mathrm{GABA}_{\mathrm{A}}$-receptor blockers bicuculline $(100 \mu \mathrm{M}$; fig. $4 \mathrm{a})$ and picrotoxin (100 $\mu \mathrm{M}$; fig. $4 \mathrm{~b})$.

These experiments show that the effect of bicuculline is fully reversible while that of picrotoxin is not. Furthermore, the results in figure 4 extend our earlier observations [20] by demonstrating that this late component of the light scattering signal monitors, directly or indirectly, $\mathrm{Cl}^{-}$movement through $\mathrm{GABA}_{\mathrm{A}}$-receptor channels.

If $\mathrm{Cl}^{-}$movement is responsible for shaping the $\mathrm{R}$-wave, we would expect that blocking $\mathrm{Cl}^{-}$channels would have a similar effect on the R-wave as that of the $\mathrm{GABA}_{\mathrm{A}}$-receptor blockers. We, therefore, examined the effect of $\mathrm{R}(+)-I A A-94$, a potent inhibitor of skeletal muscle and epithelial $\mathrm{Cl}^{-}$channels, on the R-wave. Figure 5 demonstrates that, at $100 \mu \mathrm{M}$ concentration, R(+)-IAA-94 does, indeed, mimic the effect of bicuculline and picrotoxin on the recovery phase of the light scattering signal.

While GABAergic terminals and $\mathrm{GABA}_{\mathrm{A}}$-receptors are present in rat PP, and GABA itself inhibits neurosecretion in the neurohypophysis [27, 29], we find no evidence for any effect of $\mathrm{GABA}_{\mathrm{A}}$-antagonists on the component of the light scattering signal (the $S$-wave) that is related to secretion of the hormones oxytocin and arginine vasopressin by the terminals of the mouse PP (neurohypophysis). Indeed, figures $4 \mathrm{c}$ and $4 \mathrm{~d}$ illustrate the complete absence of any effect of bicuculline and picrotoxin on the S-wave (or the E-wave) of the light scattering signal in the mouse neurohypophysis.

The PP is electrically excitable [31], and when stained with voltage-sensitive dyes $[12,13,16-18]$ exhibits fast extrinsic optical signals that are readily identified as action potentials. PI cells, on the other hand, although capable of generating action potentials [32], are not directly excited by stimulation of the infundibular stock and neither the extrinsic optical signal (not shown) nor the light scattering signal from PI tissue exhibits a rapid response fol- 


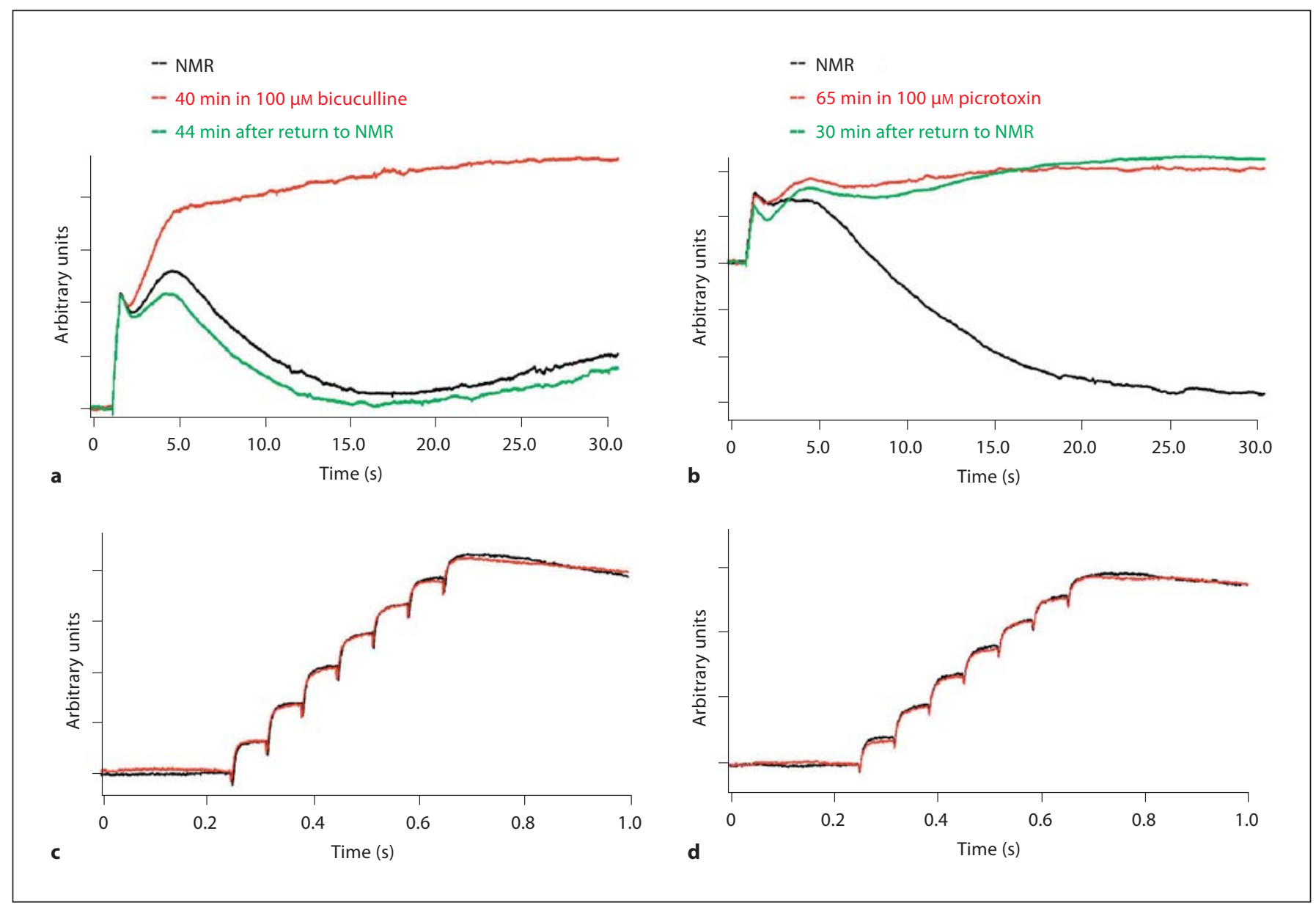

Fig. 4. $\mathrm{GABA}_{\mathrm{A}}$-receptor blockers modify the light scattering signal recorded from the neurointermediate lobe. a $100 \mu \mathrm{M}$ bicuculline modifies the shape of the R-wave of the light scattering signal recorded from the neurointermediate lobe in response to the trains of seven electrical stimuli $(500 \mu \mathrm{s}$ at $16 \mathrm{~Hz})$ applied to the infundibular stalk. Black trace: light scattering signal recorded in normal mouse Ringer's solution (NMR) before application of bicuculline. Red trace: light scattering signal after $40 \mathrm{~min}$ in $100 \mu \mathrm{M}$ bicuculline. Green trace: light scattering signal recorded $44 \mathrm{~min}$

lowing action potential stimulation (see fig. 8, green trace). Despite the differences in electrical excitability of PP and PI, the light scattering signal that we observe in response to electrical stimulation applied to the axons that compose the infundibular stalk is actually a combination of the intrinsic optical change generated in the neural (PP) and intermediate (PI) lobes of the pituitary. In order to separate the observed light scattering change into components having identifiable anatomical origins, we attempted to dissect away as much as possible of the PI from the PP.

after return to NMR. b $100 \mu \mathrm{M}$ picrotoxin also modifies the shape of the R-wave of the light scattering signal recorded from the neurointermediate lobe in response to the trains of seven electrical stimuli $(500 \mathrm{~ms}$ at $16 \mathrm{~Hz})$ applied to the infundibular stalk. Black trace: light scattering signals recorded in NMR before adding picrotoxin; red trace recorded after $65 \mathrm{~min}$ in $100 \mu \mathrm{M}$ picrotoxin; green trace recorded $30 \mathrm{~min}$ after return to NMR. Unlike bicuculline, the effects of picrotoxin were irreversible. $\mathbf{c}$ and $\mathbf{d}$ are expanded versions of the traces in $\mathbf{a}$ and $\mathbf{b}$.

Although a complete separation of the PI is difficult because it carries the risk of compromising the integrity of the neurohypophysis, we were able to obtain interesting results following manual separation of the PI. Some of these results are shown in figures 6 and 7.

Figure 6 illustrates the consistent observation that, upon surgical removal of most of the PI, the effects of bicuculline (fig. 6a) and/or picrotoxin (fig. 6b) on the Rwave of the light scattering signal are greatly diminished. Indeed, there is virtually no difference in the light scattering signal in the presence or absence of either GABA- 


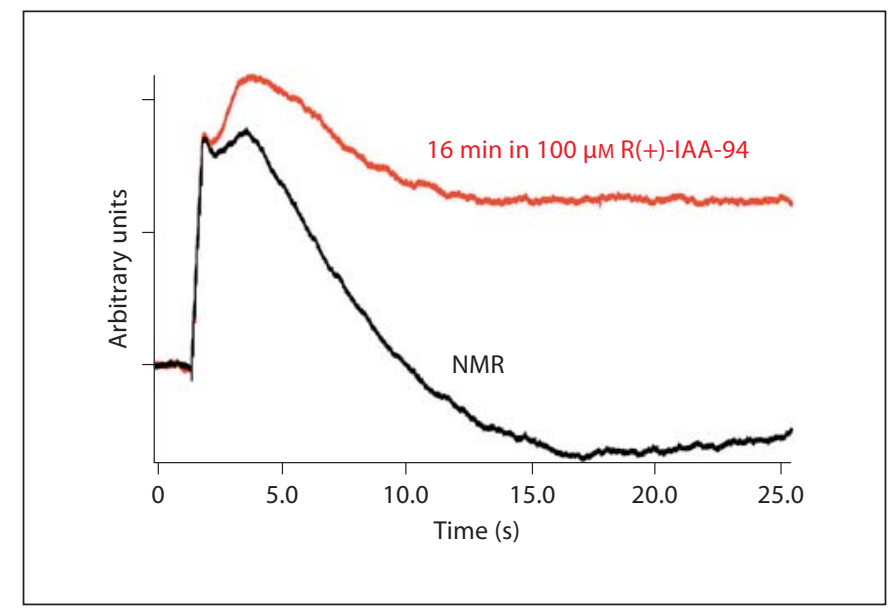

Fig. 5. The effect of a chloride channel blocker on the R-wave of the light scattering signal recorded from the neurointermediate lobe (PP plus PI). The black trace shows the light scattering signal recorded in normal mouse Ringer's solution (NMR) from the neurointermediate lobe in response to the same train of seven electrical stimuli applied to the infundibular stalk. The red trace illustrates the effect of 16-min exposure to the $\mathrm{Cl}^{-}$channel blocker, $\mathrm{R}(+)-\mathrm{IAA}-94$, at $100 \mu \mathrm{M}$. The effect is very similar to that of the $\mathrm{GABA}_{\mathrm{A}}$-receptor blockers, bicuculline and picrotoxin.

receptor blocker. These results strongly suggest that bicuculline and picrotoxin bind to $\mathrm{GABA}_{\mathrm{A}}$ receptors found primarily on PI cells. The change in the profile of the $\mathrm{R}-$ wave upon removal of the PI is also noteworthy (compare, for example, the control curves in fig. 6 with those in fig. $3-5)$ as the resulting R-wave has its origin primarily in PP.

For separating the two signals, a non-invasive alternative to physically dividing the tissue involves using a high numerical aperture objective to monitor the light scattering signals coming from different areas, as well as from different depths within the neurointermediate lobe. Figure 7 shows one such experiment. Signals from the PI were obtained by recording transmitted light at the edge of the preparation, where the PP tissue is thin to nonexistent, and by using a diaphragm in the image plane of the microscope to select a field of view containing exclusively what could be identified as PI tissue. In addition, signals could be monitored, at different depths of focus, from the central region of the neurointermediate lobe, but at increasing distances from the PI, which lay against the bottom of the chamber. The red trace was recorded from the whole tissue with an open diaphragm in the image plane of the microscope. The black trace was recorded from the upper-center of the neurointermediate lobe, where the scattering is dominated by neurohypophysial
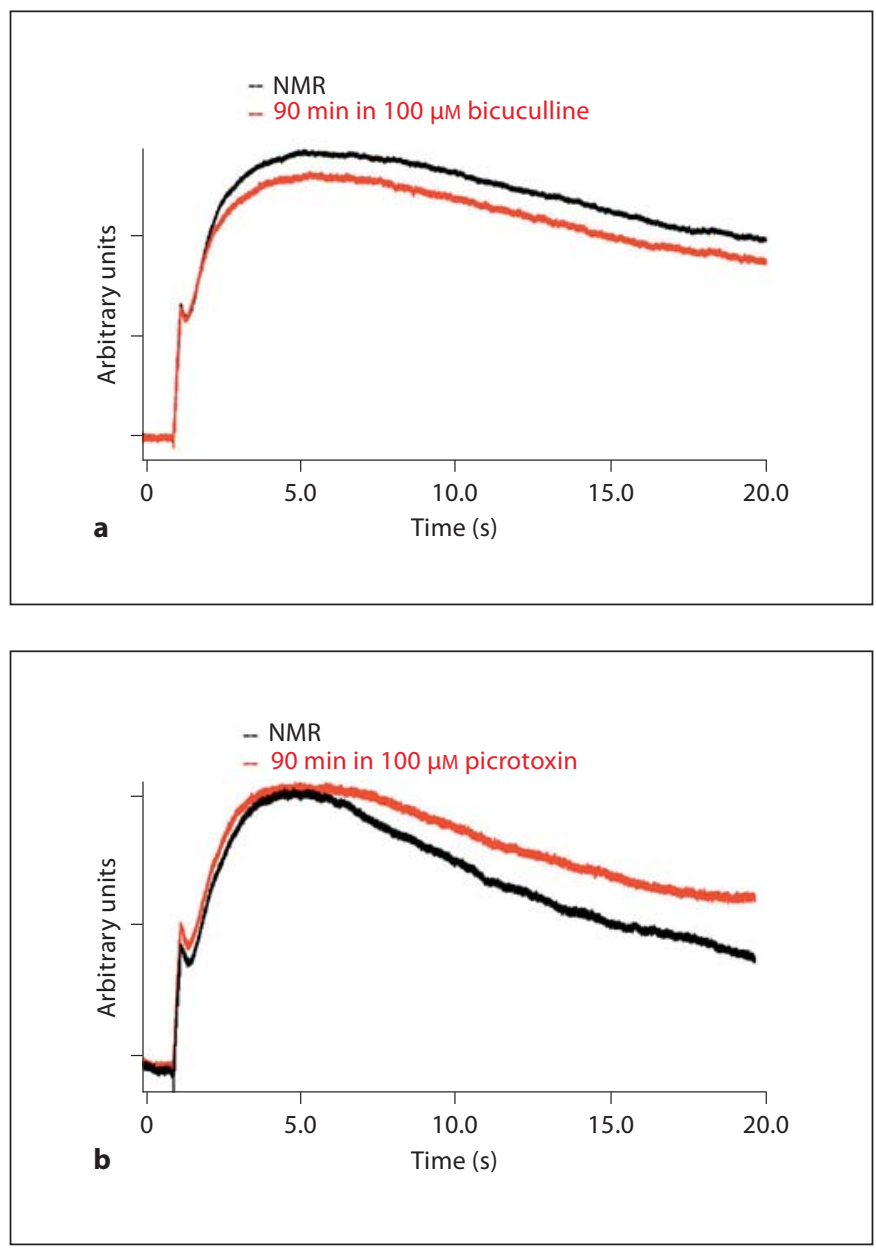

Fig. 6. With the surgical removal of most of the PI, the effects of bicuculline (a) and picrotoxin (b) on the R-wave of the light scattering signal are greatly diminished. a Black trace: PP in normal mouse Ringer's solution (NMR); red trace: $90 \mathrm{~min}$ in $100 \mu \mathrm{M} \mathrm{bi-}$ cuculline. b Black trace: PP in NMR; red trace: 90 min in $100 \mu \mathrm{M}$ picrotoxin.

terminals (and the dense core secretory granules contained within them). The green trace was recorded from the edge of the neurointermediate lobe, where only the PI lies in the light path. Note that this trace completely lacks the fast light scattering components (E-wave and S-wave).

Using the same technique employed in figure 7 , we found additional evidence for the conclusion that the GABA receptors responsible for shaping the downward deflection of the R-wave are confined to the PI. This is illustrated in figure 8. In this experiment, application of bicuculline (100 $\mu \mathrm{M}$; red trace) completely abolished the light scattering signal having its origin in the PI (lower black trace), but had little or no effect (green trace) on the 


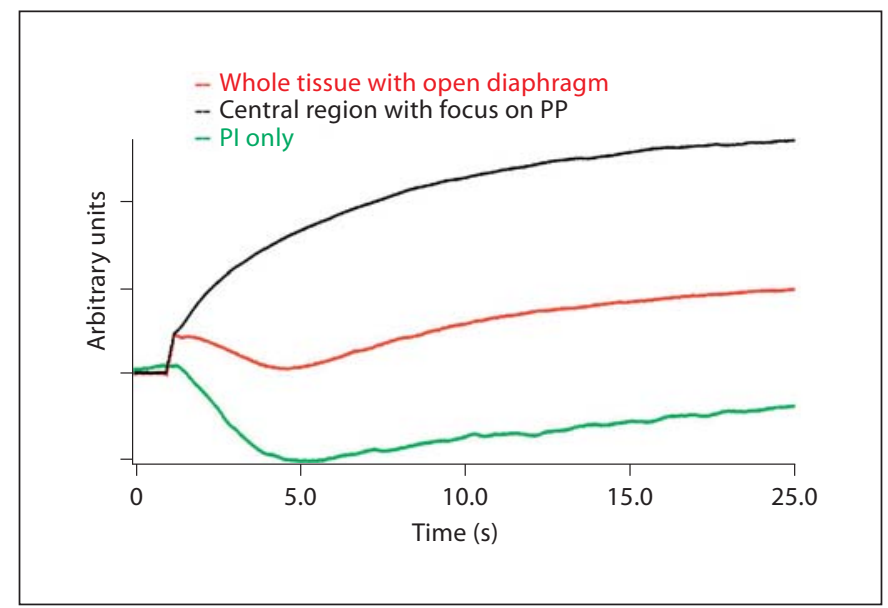

Fig. 7. Optical separation of light scattering signals from the neurointermediate lobe in response to the same train of seven electrical stimuli as in figure 1 applied to the infundibular stalk. Red trace: recording from the whole tissue with open diaphragm in the image plane of the microscope; black trace: recording from the central region of the neurointermediate lobe, but with the focus on the PP where the scattering is dominated by the neurohypophysial terminals; green trace: recording from the edge of the neurointermediate lobe, where only the PI lies in the light path. In this case, there is no fast light scattering signal. All traces were recorded from the same preparation.

light scattering signal originating in the neurohypophysis (PP, upper black trace). The same results were obtained using $100 \mu \mathrm{M}$ picrotoxin (data not shown).

The results presented above implicated GABA as a potent modulator of the R-wave of the light-scattering signal and identify the PI as the locus where the most relevant GABA receptors are expressed. However, the evidence presented thus far relied on GABA released upon electrical stimulation of the infundibular stalk, and cannot preclude synergistic interactions between GABA and other neuropeptides or neurotransmitters, either co-secreted or released from nearby terminals in response to the same electrical input.

To examine unambiguously whether GABA itself has a direct effect on the PI, we monitored the light-scattering changes exclusively from the PI portion of the neurointermediate lobe during direct bath application of the neurotransmitter. The preparation exhibited a dose-dependent response to GABA application at concentrations ranging from 0.1 to $4 \mathrm{mM}$. Figure 9 shows the result for $4 \mathrm{mM}$. The black trace illustrates the intrinsic optical signal recorded from PI while the neurointermediate lobe was superfused with normal mouse Ringer's solution

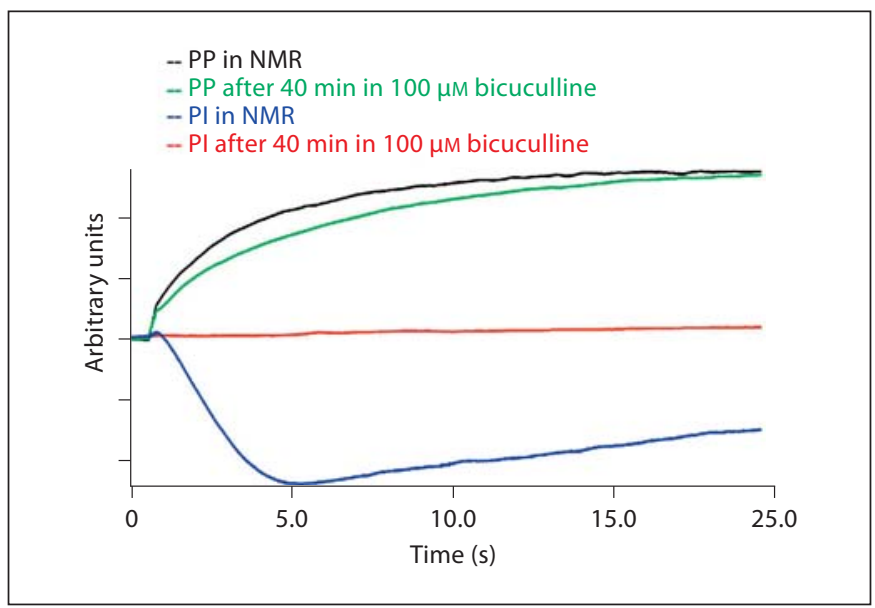

Fig. 8. The effects of bicuculline are limited to the light scattering changes recorded from the PI. Black trace: light scattering signals from the PP recorded in normal mouse Ringer's solution (NMR) in response to the same train of seven electrical stimuli applied to the infundibular stalk; green trace: the light scattering changes recorded from the PP after $40 \mathrm{~min}$ in $100 \mu \mathrm{M}$ bicuculline. The blue trace shows the light scattering signal recorded from the PI in NMR in response to the same train of seven electrical stimuli applied to the infundibular stalk; the red trace illustrates the response in the PI after $40 \mathrm{~min}$ in $100 \mu \mathrm{M}$ bicuculline.

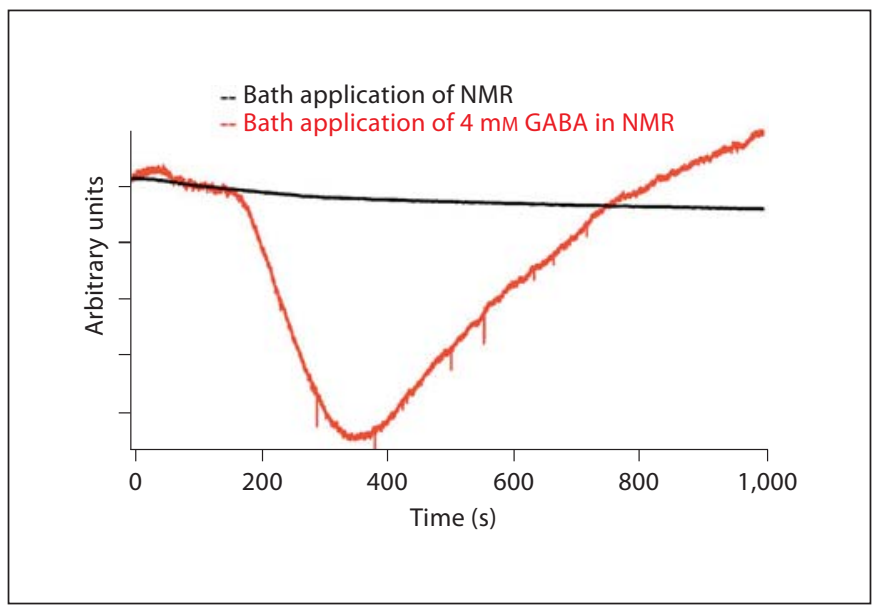

Fig. 9. The light scattering changes recorded from the PI in response to bath application of GABA. Black trace: response to bath application of normal mouse Ringer's solution (NMR; control); red trace: response to bath application of Ringer's solution containing 4 mM GABA. 

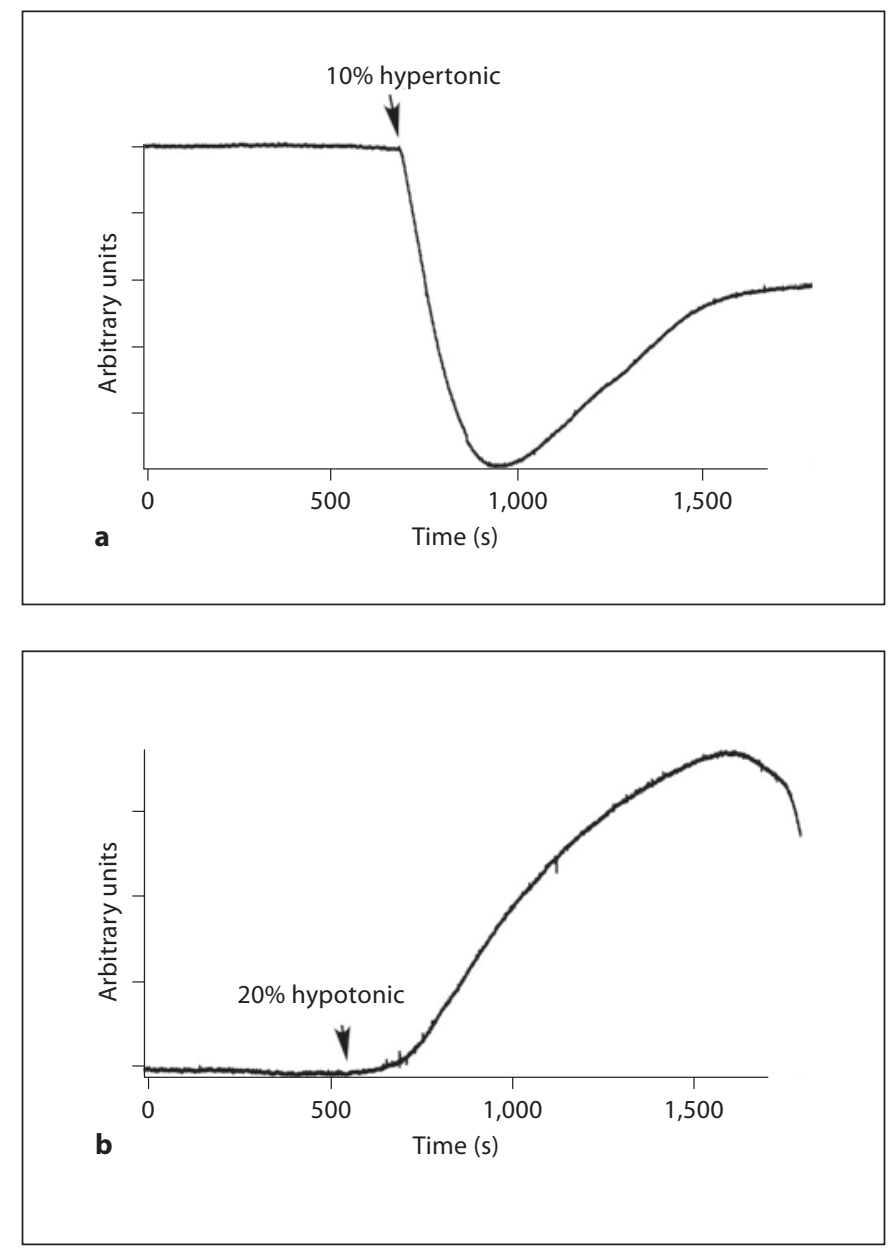

Fig. 10. Changes in light scattering in response to acute changes in bath osmolarity. a Transient decrease in transmitted light intensity (increase in light scattering) in response to a Ringer's solution made $10 \%$ hypertonic with sucrose. b Transient increase in transmitted light intensity (decrease in light scattering) in response to application of a Ringer's solution made hypotonic by the addition of $20 \%$ distilled $\mathrm{H}_{2} \mathrm{O}$.

(NMR). The red trace shows the intrinsic signal recorded from the same spot while the tissue was exposed to a solution containing $4 \mathrm{~mm}$ GABA. Both traces were recorded in the absence of electrical stimulation. The intrinsic optical change in response to a direct application of GABA resembles qualitatively the records shown in figure 7 (green trace) and figure 8 (black traces), all of which exhibited the recovery phase (R-wave) of the light scattering signal from the PI following electrical stimulation of the infundibular stalk.

We have also observed that bath application of GABA produces the same effect on the optical properties of the
PI as does a solution made $10 \%$ hypertonic with sucrose, a solution that induces cell shrinkage. This is illustrated in figure 10.

\section{Discussion}

The hypothalamus is the portion of the brain where neural signals are converted to humoral ones. Secretion of arginine vasopressin and oxytocin by the nerve terminals and axonal varicosities of the neurohypophysis (PP) has been studied extensively as a function of electrical activity in the magnocellular neurons of the hypothalamus. The role of GABA in hormone release, however, is less well understood. GABA appears to act as a regulatory factor in the control of hormone secretion in different parts of the pituitary gland. The control mechanisms involve GABAergic terminals of the $\mathrm{PP}$ as well as $\mathrm{GABA}_{\mathrm{A}}$ and $\mathrm{GABA}_{\mathrm{B}}$ receptors of the PP and PI. Neuronal control of pituitary function by GABA via direct innervation of secretory cells of the PI by the axon terminals of hypothalamic neurons was demonstrated by immunodetection of GABA $[33,34]$, by intracellular recordings from the PI in response to both pituitary stalk stimulation and exogenous GABA application [26, 28], by immunohistochemical studies using antibodies to the enzyme responsible for production of GABA, viz., glutamate decarboxylase $[25,27]$, by measurement of glutamate decarboxylase activity [24], and by immunohistochemical localization of the GABA stores in nerve terminals using antibodies to the vesicular GABA transporter [35]. Although $\mathrm{GABA}_{\mathrm{A}}$ receptors are present in both the $\mathrm{PP}$ and in the PI $[33,34]$, the GABA-activated currents in the PI are much larger [36], and this can readily account for the result that the R-wave is seen predominantly in the PI. Our measurements of intrinsic optical changes in the neurointermediate lobe of the mouse pituitary gland add to the current understanding of the role of central GABAergic innervation of the pituitary.

GABA appears to cause the shrinkage of neurons in embryonic brainstem slices [9], if the reported changes in light scattering are correctly interpreted as changes in extracellular volume [8]. Using dynamic high-bandwidth atomic force microscopy, our laboratory recently demonstrated that light scattering changes in the electrically stimulated PP are associated with volume changes in neurohypophysial terminals [10]. To establish the correlation between light scattering in the PI and the possible shrinkage/swelling of tissue provoked by bath application of GABA (fig. 9) we recorded light scattering signals in 
response to acutely altered osmolarity of the bathing solution (fig. 10a, b). Figure 10a illustrates the transient decrease in transmitted light intensity when the PI is shrunken as the result of flowing a Ringer's solution rendered $10 \%$ hypertonic with sucrose. In contrast, figure $10 \mathrm{~b}$ demonstrates the increased transparency associated with swelling of the PI resulting from changing the Ringer's solution bathing the neurointermediate lobe to one made hypotonic by the addition of $20 \%$ distilled $\mathrm{H}_{2} \mathrm{O}$ to the Ringer's solution. From these measurements we can conclude that in PI tissue, GABA produces an intrinsic optical effect analogous to the effect of hypertonic solution - the transparency of the tissue decreases along with shrinkage. An alternative hypothesis, viz., that the light scattering change observed in the PI is related to $\mathrm{Ca}^{2+}$ entry and subsequent exocytosis and/or endocytosis, is not consistent with our observation that the light scattering change that follows bath application of GABA is not reduced in magnitude when $\mathrm{Ca}^{2+}$ entry is prevented by $\mathrm{Cd}^{2+}(0.5 \mathrm{mM})$.

Volume changes are intimately related to water homeostasis and are critical for normal brain functioning. For example, a $\mathrm{K}^{+}$and $\mathrm{Cl}^{-}$channel-mediated volume decrease occurs early, before the characteristic ultrastructural or biochemical events associated with apoptosis [37]. Moreover, cell volume decrease may be inhibited pharmacologically by blocking the $\mathrm{K}^{+}$or $\mathrm{Cl}^{-}$channels implicated in cellular volume regulation [38]. Further, the small volume changes associated with exocytosis in nerve terminals $[2,3]$ affect extracellular ion concentrations and, thence, volume. The volume regulation and ionic homeostasis contributed by plasma membrane $\mathrm{Cl}^{-}$channels [39], including $\mathrm{GABA}_{\mathrm{A}}$ receptors, is carried out in dynamic equilibrium with the operation of various transporters, with water movement mediated by aquaporins and by co-transporters that are expressed in the plasma membrane [40]. As already noted, we have observed (fig. 9) that bath application of GABA produces the same effect on the optical properties of the PI as does a solution made $10 \%$ hypertonic with sucrose, a solution that induces cell shrinkage. The volume restoration that follows may be due to the turnover of the GAT-1 GABA-transporter [41]. Thus, we can speculate that if water secretion associated with exocytosis [3] and/or cell shrinkage due to direct GABAergic innervation does take place, the transporter (GAT-1) may supply the water that restores cell volume.

The light scattering measurements presented here allow us to conclude that: (1) the component of the longterm optical response ( $\mathrm{R}$-wave) that is sensitive to $\mathrm{Cl}^{-}$-ion movements reflects changes in the PI, and (2) the full time-course of the response takes minutes and is likely, therefore, to encompass not only $\mathrm{Cl}^{-}$channel opening by GABA, but also some other processes that are responsible for restoration of the physiological $\mathrm{Cl}^{-}$concentrations. Note that the R-wave frequently undershoots the baseline and that full recovery usually takes minutes. It is reasonable to suppose that the complex shape of the R-wave is partially determined by the GAT-1 transporter, which could account for its biphasic shape, but this remains to be clarified by future experiments.

The data presented here provide optical evidence for the idea that the recovery phase (R-wave) of the light scattering signal reflects events which are involved in modulating the process of hormone release by the PI, and also provide some optical and pharmacological arguments for a central GABAergic innervation of the pituitary, where GABA acts as a factor in hormone release.

\section{Acknowledgment}

Supported by USPHS grants NS16824 and NS40966 to B.M.S.

\section{References}

1 Hsu SF, Jackson MB: Rapid exocytosis and endocytosis in nerve terminals of the rat posterior pituitary. J Physiol 1996;494:539-553.

$\checkmark 2$ Rosenboom H, Lindau M: Exo-endocytosis and closing of the fission pore during endocytosis in single pituitary nerve terminals internally perfused with high calcium concentrations. Proc Natl Acad Sci USA 1994;91: 5267-5271.
- 3 Tsuboi T, Kikuta T, Sakurai T, Terakawa S: Water secretion associated with exocytosis in endocrine cells revealed by micro forcemetry and evanescent wave microscopy. Biophys J 2002;83:172-183.

4 Mansvelder HD, Kits KS: The relation of exocytosis and rapid endocytosis to calcium entry evoked by short repetitive depolarizing pulses in rat melanotropic cells. J Neurosci 1998; 18:81-92.
5 Bernstein EM, Quick MW: Regulation of gamma-aminobutyric acid (GABA) transporters by extracellular GABA. J Biol Chem 1999;274:889-895.

$6 \mathrm{Kim} \mathrm{G}$, et al: High bandwidth atomic force microscopy reveals a mechanical spike during the action potential in mammalian nerve terminals. Biophys J 2007;92:86a. 
7 Salzberg BM, Obaid AL, Gainer H: Large and rapid changes in light scattering accompany secretion by nerve terminals in the mammalian neurohypophysis. J Gen Physiol 1985;86: 395-411.

-8 Holthoff K, Witte OW: Intrinsic optical signals in rat neocortical slices measured with near-infrared dark-field microscopy reveal changes in extracellular space. J Neurosci 1996;16:2740-2749.

-9 Momose-Sato Y, Sato K, Hirota A, Kamino K: GABA-induced intrinsic light-scattering changes associated with voltage-sensitive dye signals in embryonic brain stem slices: coupling of depolarization and cell shrinkage. J Neurophysiol 1998;79:2208-2217.

$>10$ Kim GH, Kosterin P, Obaid AL, Salzberg BM: A mechanical spike accompanies the action potential in mammalian nerve terminals. Biophys J 2007;92:3122-3129.

-11 Salzberg BM, Obaid AL: Optical studies of the secretory event at vertebrate nerve terminals. J Exp Biol 1988;139:195-231.

12 Obaid AL, Flores R, Salzberg BM: Calcium channels that are required for secretion from intact nerve terminals of vertebrates are sensitive to omega-conotoxin and relatively insensitive to dihydropyridines: optical studies with and without voltage-sensitive dyes. J Gen Physiol 1989;93:715-729.

$\checkmark 13$ Parsons TD, Obaid AL, Salzberg BM: Aminoglycoside antibiotics block voltage-dependent calcium channels in intact vertebrate nerve terminals. J Gen Physiol 1992;99:491504.

14 Salzberg B, et al: Calcium release from intraterminal stores plays a direct role in release from peptidergic nerve terminals in mammals: Evidence from light scattering in mouse neurohypophysis. J Gen Physiol 1997; 110:16A.

15 Bennett CB, Muschol M: Large neurohypophysial varicosities amplify action potentials: results from numerical simulations. Endocrinology 2009;150:2829-2836.

-16 Gainer H, Wolfe SA Jr, Obaid AL, Salzberg BM: Action potentials and frequency-dependent secretion in the mouse neurohypophysis. Neuroendocrinology 1986;43:557-563.

- 17 Muschol M, Kosterin P, Ichikawa M, Salzberg BM: Activity-dependent depression of excitability and calcium transients in the neurohypophysis suggests a model of 'stuttering conduction'. J Neurosci 2003;23: 11352-11362.
18 Salzberg BM, Obaid AL, Senseman DM, Gainer H: Optical recording of action potentials from vertebrate nerve terminals using potentiometric probes provides evidence for sodium and calcium components. Nature 1983;306:36-40.

19 Muschol M, Salzberg BM: Dependence of transient and residual calcium dynamics on action-potential patterning during neuropeptide secretion. J Neurosci 2000;20:67736780.

20 Obaid AL, et al: Stilbene derivatives and chloride replacement by impermeant anions dramatically alter a late component of the light scattering change in mammalian nerve terminals. Biol Bull 1989;177:325.

21 De Beer GR: The evolution of the pituitary. J Exp Biol 1924;1:272-291.

22 Rumyantsev SL, et al: Low frequency noise and long-term stability of non-coherent light sources. J Appl Phys 2004;96:966-969.

23 Salzberg BM, Kosterin PV, Muschol M, et al: An ultra-stable non-coherent light source for optical measurements in neuroscience and cell physiology. J Neurosci Methods 2005; 141:165-169.

24 Oertel WH, Mugnaini E, Tappaz ML, et al: Central GABAergic innervation of neurointermediate pituitary lobe: biochemical and immunocytochemical study in the rat. Proc Natl Acad Sci USA, 1982;79:675-679.

25 Poisbeau P, René F, Egles C, et al: Characterization of functional GABAergic synapses formed between rat hypothalamic neurons and pituitary intermediate lobe cells in coculture: $\mathrm{Ca}^{2+}$ dependence of spontaneous IPSCs. J Neurosci 1996;16:4835-4845.

26 Tomiko SA, Taraskevich PS, Douglas WW: GABA acts directly on cells of pituitary pars intermedia to alter hormone output. Nature 1983;301:706-707.

27 Vincent SR, Hokfelt T, Wu JY: GABA neuron systems in hypothalamus and the pituitary gland: immunohistochemical demonstration using antibodies against glutamate decarboxylase. Neuroendocrinology 1982;34: 117-125.

28 Williams PJ, MacVicar BA, Pittman QJ: Identification of a GABA-activated chloridemediated synaptic potential in rat pars intermedia. Brain Res 1989;483:130-134.
9 Zhang SJ, Jackson MB: $\mathrm{GABA}_{\mathrm{A}}$ receptor activation and the excitability of nerve terminals in the rat posterior pituitary. J Physiol 1995;483:583-595.

30 Demeneix BA, et al: $\mathrm{GABA}_{\mathrm{A}}$ and $\mathrm{GABA}_{\mathrm{B}}$ receptors on porcine pars intermedia cells in primary culture: functional role in modulating peptide release. Neuroscience 1986;17: 1275-1285.

31 Douglas WW, Poisner AM: Stimulus-secretion coupling in a neurosecretory organ: the role of calcium in the release of vasopressin from the neurohypophysis. J Physiol 1964; 172:1-18.

32 McBurney RN, Kehl SJ: Electrophysiology of neurosecretory cells from the pituitary intermediate lobe. J Exp Biol 1988;139:317-328.

-33 Buijs RM, van Vulpen EH, Geffard M: Ultrastructural localization of GABA in the supraoptic nucleus and neural lobe. Neuroscience 1987;20:347-355.

34 Rabhi M, Onteniente B, Kah O, Geffard M Calas A: Immunocytochemical study of the GABAergic innervation of the mouse pituitary by use of antibodies against gammaaminobutyric acid (GABA). Cell Tissue Res 1987;247:33-40.

35 Mayerhofer A, Höhne-Zell B, Gamel-Didelon $\mathrm{K}$, et al: Gamma-aminobutyric acid (GABA): a para- and/or autocrine hormone in the pituitary. FASEB J 2001;15:1089-1091.

-36 Schneggenburger R, Lopez-Barneo J: Patchclamp analysis of voltage-gated currents in intermediate lobe cells from rat pituitary thin slices. Pflugers Arch 1992;420:302-312.

37 Yu SP, Choi DW: Ions, cell volume, and apoptosis. Proc Natl Acad Sci USA 2000;97:93609362.

38 Maeno E, Ishizaki Y, Kanaseki T, et al: Normotonic cell shrinkage because of disordered volume regulation is an early prerequisite to apoptosis. Proc Natl Acad Sci USA 2000;97:9487-9492.

39 Jentsch TJ, Stein V, Weinreich F, Zdebik AA Molecular structure and physiological function of chloride channels. Physiol Rev 2002; 82:503-568.

40 Richerson GB, Wu Y: Dynamic equilibrium of neurotransmitter transporters: not just for reuptake anymore. J Neurophysiol 2003;90: 1363-1374.

-41 Palacin M, Estévez R, Bertran J, Zorzano A: Molecular biology of mammalian plasma membrane amino acid transporters. Physiol Rev 1998;78:969-1054. 